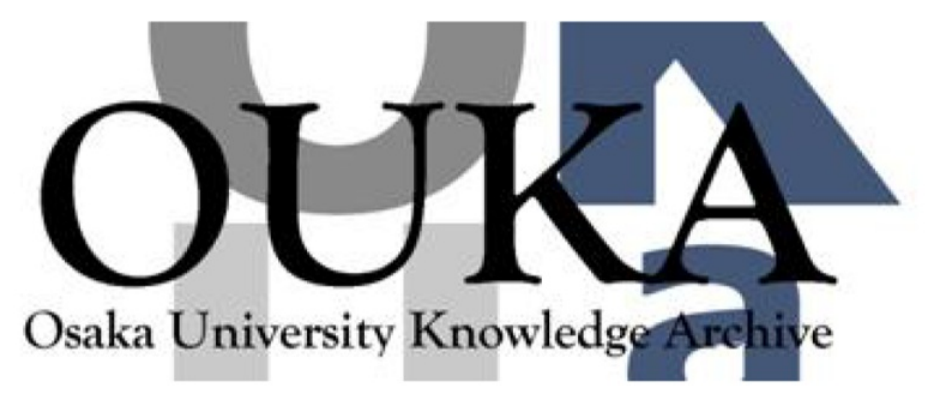

\begin{tabular}{|c|l|}
\hline Title & $\begin{array}{l}\text { Bonding Strength of DLC Film on Zirconia } \\
\text { Coating Prepared by Gas Tunnel Type Plasma } \\
\text { Spraying }\end{array}$ \\
\hline Author(s) & $\begin{array}{l}\text { Kobayashi, Akira; Zhang, Jialiang; Yatsuzuka, } \\
\text { Mitsuyasu }\end{array}$ \\
\hline Citation & Transactions of JWRI. 35(2) p. 29-p.34 \\
\hline Issue Date & $2006-12$ \\
\hline oaire:version & VoR \\
\hline URL & https://doi.org/10.18910/6964 \\
\hline rights & \\
\hline Note & \\
\hline
\end{tabular}

Osaka University Knowledge Archive : OUKA

https://ir. Library. osaka-u. ac. jp/

Osaka University 


\title{
Bonding Strength of DLC Film on Zirconia Coating Prepared by Gas Tunnel Type Plasma Spraying ${ }^{\dagger}$
}

\author{
KOBAYASHI Akira*, Jialiang ZHANG**, and YATSUZUKA Mitsuyasu***
}

\begin{abstract}
Plasma sprayed zirconia coatings are now commonly used as the thermal barrier coatings (TBC) for high-temperature parts in many mechanical applications such as the engines of automobiles, planes and rockets. However, coating adhesion is frequently the cause for the failure of the coatings. As the same as the zirconia coatings, the deposition of diamond-like carbon (DLC) films on the metal substrate has some problem in the adhesion between DLC film and the substrate. But the adhesion property was improved by the interlayer of a hard ceramic coating on the metal substrate. In order to show the failure mechanism for coating adhesion, zirconia coatings with different thickness were prepared on stainless steel and/or aluminum substrates by a novel kind of gas tunnel type plasma spraying. The as-sprayed coatings were firstly polished and then subjected to deposition of diamond-like carbon (DLC) films using hydrocarbon gas as the carbon source. The adhesion of the DLC covered zirconi coatings was evaluated by the scratch test method. The evaluation showed that thicker as-sprayed zirconia coatings on aluminum alloy substrate showed much higher scratch durability, even with thinner zirconia coatings. The porosity and hardness of as-sprayed coatings were measured on the coating cross-sections using a micro-hardness tester and optical microscopy. The results showed that thicker coatings had higher hardness and lower porosity. The adhesion failure of DLC films on zirconia coatings is caused by two different mechanisms: one is the separation of the DLC films from the zirconia coatings and the other is the breaking of the DLC films under stress load because of the brittleness of the material. From the microscopic photos of the scratch tracks, the adhesion failure of DLC film on the thinner zirconia coatings is due to the flaking of DLC film by the distortion of aluminum alloy substrate, while the adhesion failure of DLC films on thicker zirconia coating is due to the chipping of the DLC film itself.
\end{abstract}

KEY WORDS: (DLC Film on $\mathrm{ZrO}_{2}$ Coating), (Scratch Test), (Adhesion Strength), (Gas Tunnel Type Plasma Spraying)

\section{Introduction}

Plasma sprayed zirconia coatings are now frequently used as the thermal barrier coatings (TBC) for high-temperature parts in many mechanical applications such as the engines of automobiles, planes and rockets because of the low thermal conductivity and porous microstructure of zirconia coatings ${ }^{1,2}$. However, coating adhesion is frequently the cause for the failure of the coatings mostly because of the spallation due to thermally grown oxide at the interfaces of coatings and substrates ${ }^{3)}$. Many effects have been employed to overcome the spallation problem of TBC coatings by developing various kinds of techniques ${ }^{4)}$ and, especially, the spallation rate can be reduced to a very low level nowadays by the achievements in coating technology ${ }^{5,6}$. On the other hand, the high surface roughness is another principal feature of sprayed coatings and therefore a high

$\uparrow$ Received on November 10, 2006

* Associate Professor

** Foreign Guest Researcher

*** Professor, University of Hyogo friction coefficient is always accompanying the coatings. However, there is still no efficient research on the effect of the roughness of as-sprayed coating surfaces on coating adhesion. In fact, sprayed coating surfaces with high roughness present high friction and therefore put high dynamic stress load on the coating during the running cycles of coated parts. Therefore it is necessary to investigate the relation between the surface roughness of plasma sprayed zirconia coatings and coating adhesion failure mechanisms.

In this paper, zirconia coatings with different thickness were prepared on aluminum alloy substrates by a novel kind of gas tunnel type plasma spraying. One of the authors developed the novel plasma spraying technique several years ago ${ }^{7,8)}$. It has been used to deposit many kinds of hard ceramic coatings including zirconia, alumina and $\mathrm{Al}_{2} \mathrm{O}_{3}+\mathrm{ZrO}_{2}$ composite coatings ${ }^{9)}$. In order

Transactions of JWRI is published by Joining and Welding Research Institute, Osaka University, Ibaraki, Osaka 567-0047, Japan 
to compare the different adhesion failure mechanisms of zirconia coatings with rough and smooth surfaces, or with higher friction and lower friction, some of the sprayed coating samples were selected to be polished and then put into a plasma-based ion implantation and deposition system to deposit diamond like carbon (DLC) films using hydrocarbon gas as carbon source. This produced coating samples with smooth surfaces and lower friction. The other as-sprayed coatings are kept with rough surfaces.

Diamond-like carbon films have excellent tribological characteristics such as high hardness, high wear resistance and low friction coefficient. It is reasonable to use DLC thin films as the lubricant for sprayed zirconia coatings when considering the practical high-temperature application environment of thermal barrier coatings. Nevertheless, the adhesion strength of DLC films deposited with normal plasma deposition methods is rather poor because of the large residual stress in DLC films ${ }^{10)}$. A plasma-based ion implantation and deposition technique was used to prepare DLC films on sprayed zirconia coatings and to reduce the residual stress in the DLC films.

The scratch durability or adhesion strength of the DLC-covered zirconia coatings on aluminum alloy substrate is evaluated by the scratch test method. The results were compared to the case of the DLC films on the aluminum substrate with $\mathrm{SiC}_{\mathrm{x}}$ interlayer. And the adhesion failure of DLC films was discussed.

The breaking of the DLC films-themselves under mechanical load because of the brittleness of the materials, causes the adhesion failure of DLC films. The coating hardness and porosity should be related to the coating brittleness. In order to show the relation, the porosity and hardness of as-sprayed coatings are measured on the coating cross sections using an optical microscopy and micro-hardness tester.

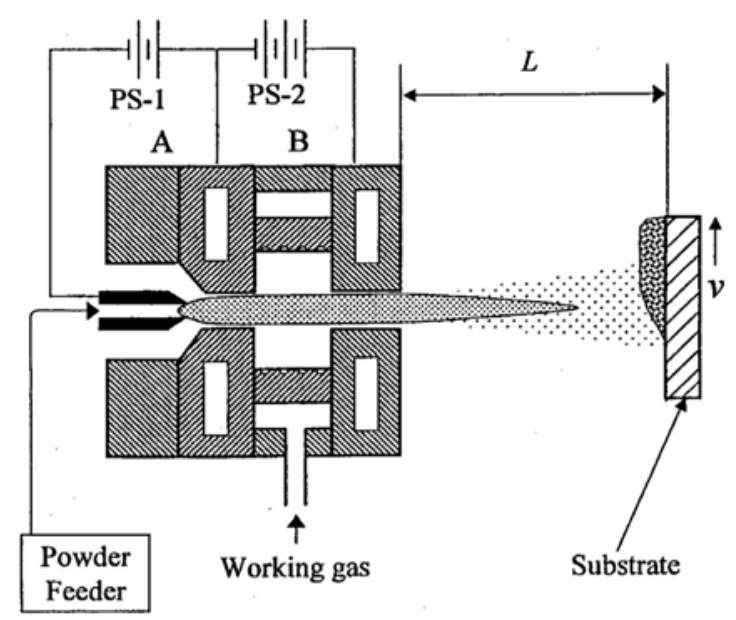

Figure 1: Schematic of the gas tunnel type plasma spraying setup.

\section{Experimental}

\subsection{Atmospheric plasma spraying assembly (APS)}

Figure 1 shows schematically the gas tunnel type plasma spraying setup. The discharge system has a specially designed spacer between the two anodes, which is characterized by gas channels on its wall in such a pattern that the gas flows into the hollow cavity of the spacer and forms a gas tunnel in its axial region. The plasma firstly forming in the hollow anode and then emitting like a flame outside the exit is well confined in the tunnel due to the thermal pinch effect and can be much higher in temperature and more stable than traditional free-standing arc torches.

The plasma spraying setup consists of one trigger cathode rod, one hollow anode and one nozzle anode and thus forms a two stage cascade arc scheme. More details of the system are presented in Ref 7. Facing the plasma, a two-dimension movable substrate holder is equipped to vary the distance between the substrates and the nozzle anode exit. The first-stage of the system is powered by a DC power source which can provide current as high as $100 \mathrm{~A}$ and power as high as $10 \mathrm{~kW}$ and triggered by a high voltage as high as $3 \mathrm{kV}$ at a pulsation frequency of $120 \mathrm{~Hz}$, while the second-stage is powered by another more powerful DC supply that can provide current as high as $500 \mathrm{~A}$ and power of $30 \mathrm{~kW}$ to amplify the plasma power. Although the spraying system is always operated in the atmosphere, it is installed in a closed chamber to avoid the powder residues polluting the Lab and to shield the torch from the ambient air.

For deposition of zirconia coatings, working argon gas is fed into the gap between the first-stage electrode pair at a nominal gas flow rate of 501/min and also carrier gas of argon is fed into the spacer cavity at a nominal rate of $1001 / \mathrm{min}$. Normally, based on the present configuration, the first-stage is successfully maintained with an arc voltage of $40-55 \mathrm{~V}$ and current of $20-80 \mathrm{~A}$, while the second-stage discharge is maintained with a voltage of $30-40 \mathrm{~V}$ and current of $300-450 \mathrm{~A}$.

\subsection{Zirconia coating preparation}

The gas tunnel type plasma spraying was used to deposit zirconia coatings on aluminum alloy (A5052) substrates under a discharge power of $20 \mathrm{~kW}$. The procedure to produce high hardness ceramic coatings by means of the gas tunnel type plasma spraying has been described in previous papers ${ }^{8)}$. Briefly speaking, the

Table 1 Spraying conditions.

\begin{tabular}{ll}
\hline Powder: & $\mathrm{ZrO}_{2}$ \\
Power input, $P(\mathrm{~kW}):$ & 20 \\
Gas flow rate, $Q(1 / \mathrm{min}):$ & 150 \\
Powder feed gas, $Q_{f}(1 / \mathrm{min}):$ & 10 \\
Spraying distance, $L(\mathrm{~mm}):$ & 40 \\
Deposition time, $t(\mathrm{~s}):$ & $10-40$ \\
Substrate: & $\mathrm{SUS} 304$ \\
Coating thickness: & $65-210 \mu \mathrm{m}$ \\
\hline
\end{tabular}


sprayed powder is fed into the plasma flame through the rear feeding inlet inside the trigger cathode rode. Coatings are formed on the substrates traversed at a spraying distance $\mathrm{L}=40 \mathrm{~mm}$. Before spraying, the square substrate plates of stainless steel SUS304 were previously sandblasted and cleaned in acetone. The substrate is $50 \mathrm{~mm} \times 50 \mathrm{~mm} \times 3 \mathrm{~mm}$. The deposition times for the samples were varied from $10-40 \mu \mathrm{s}$. and 3 different samples were prepared respectively with thickness about $65 \mu \mathrm{m}, 185 \mu \mathrm{m}$ and $210 \mu \mathrm{m}$. The detail of the spraying conditions is included in Table 1. From the as-sprayed coating samples, some were chosen to polish and then used to deposit DLC films in order to provide samples with smooth surfaces and lower surface friction coefficients.

\subsection{Microstructure and hardness characterization}

The cross section morphologies of the coatings were examined with an optical microscope to detect porosity in the coatings. Micro-structural characterization of coatings involves quantitative measurements of geometrical features such as porosity (in the form of voids, cracks and other defects) and analysis of material aspects of the coatings such as splat structure, interfaces, phases, etc. In this research, the optical microscope is equipped with a CCD camera for image acquisition. Micrographs with two magnifications (X 200 and X 400) of the polished coating cross sections were used for determining the porosity by image analysis software. The microstructure components can be represented in the images by gray level variation. Pores appear dark, which permit them to be distinguished and quantified. By rating the pore area to the cross-section, 2-D coating porosity assessments can be made.

The coating micro-hardness was measured on the coating cross-sections instead of the coating surfaces using a microscopic hardness tester, because the micro-hardness is distributed with gradient over the coating cross-sections. Several positions were chosen at different thickness to measure the hardness and then an average hardness calculated.

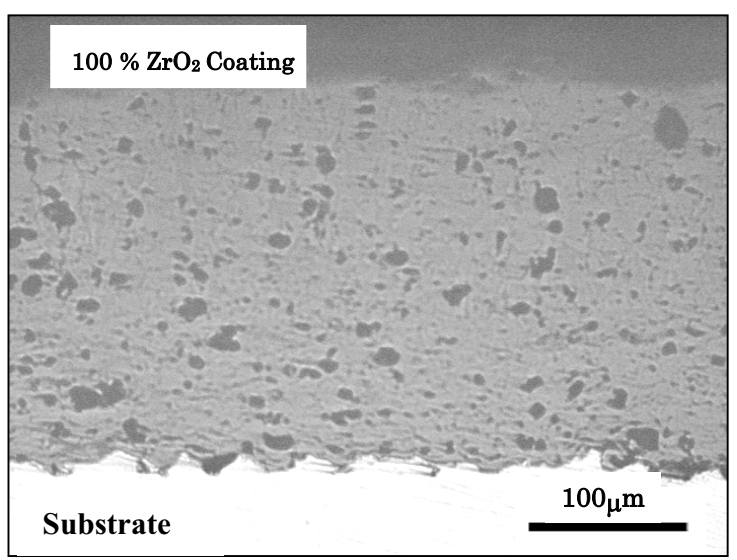

Fig.2 The cross-sectional photo of $\mathrm{ZrO}_{2}$ coating $(210 \mu \mathrm{m})$.

\subsection{DLC film deposition}

DLC films were prepared using a plasma based ion implantation and deposition system by superimposing RF power pulses for plasma generation and negative high-voltage pulses for ion implantation alternately on substrates through a joint matching circuit. In the process, the substrates worked as an RF antenna and therefore RF plasma pulses were generated around the substrates. The negative high-voltage pulses were applied to the substrates $50 \mu$ s later after the RF pulses. During the negative high-voltage pulses, ions of the RF plasma pulses were implanted into the substrates. Simultaneously, secondary electrons emitted by the ion implantation were accelerated by the negative sheath to ionize or dissociate more gas atoms and molecules, generating many more ions and radicals for DLC film deposition on the substrates. As the final result of the process, uniform DLC coating could be deposited on all the surface of the substrates.

The chosen samples of sprayed zirconia coatings were firstly polished and then cleaned by argon plasma sputtering before becoming the substrates for DLC deposition. The precursor gas for DLC deposition was methane, acetylene and toluene. When the gas pressure was $0.5 \mathrm{~Pa}$, the deposition rate of DLC film using toluene in the plasma was $0.5 \mu \mathrm{m} / \mathrm{h}$. According to the deposition rate, the final thickness of DLC films on all the chosen samples was evaluated to be about $1 \mu \mathrm{m}$.

\subsection{Scratch test for adhesion and scratch durability}

The scratch durability or adhesion strength of the DLC-covered zirconia coatings on aluminum alloy substrate were evaluated by the scratch test method. A scratch tester from Revetest, CSEM was equipped with a spherical diamond indenter of $0.4 \mathrm{~mm}$ in diameter. During the tests, the scratching speed for all the samples was $10 \mathrm{~mm} / \mathrm{min}$ and the loading rate was $100 \mathrm{~N} / \mathrm{min}$. The scratch regions were observed with a $\mathrm{CCD}$ microscope (KEYENCE, VH-800). From the microscopic photos of scratch tracks, the track length before coating breaking was measured as the indication of the coating adhesion or scratch durability.

\section{Results}

\subsection{Microstructure and hardness}

The optical microscopic photos for the different as-sprayed zirconia coatings were taken over their polished cross-sections. Figure 2 shows the photo of a coating cross-section with thickness of $200 \mu \mathrm{m}$, showing the microstructure of pores. The photos were also used to analyze quantitatively the porosity profile over the coating cross-sections and to obtain an average porosity.

Figure 3 shows the porosity and micro-hardness of the coating samples with the thickness as a variable. The average porosity of the coatings decreased with the coating thickness, which was probably attributed to the fact that the surface temperature of coatings was getting higher during spraying due to the higher thermal barrier 


\section{Bonding Strength of DLC Film on Zirconia Coating Prepared by Gas Tunnel Type Plasma Spraying}

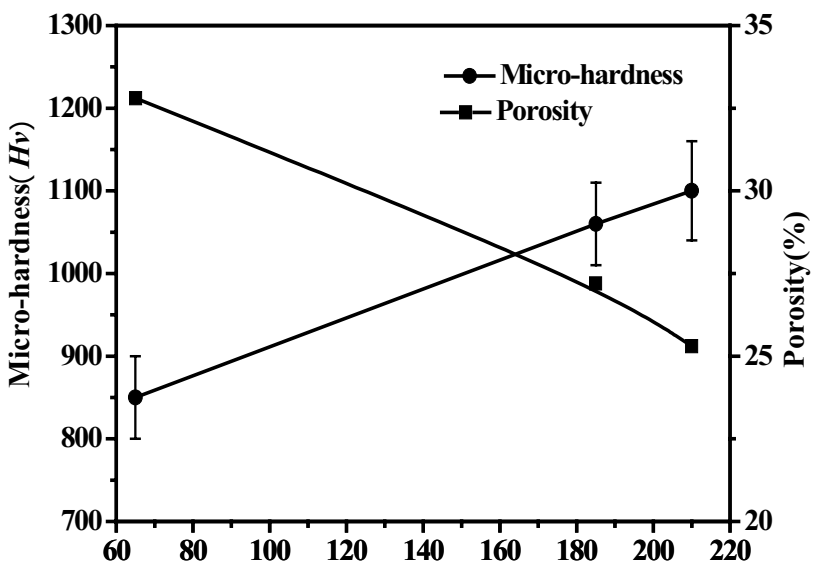

Fig.3 The hardness and porosity of $\mathrm{ZrO}_{2}$ coating v.s thickness.

effect of thicker coatings. Higher surface temperature was more helpful for the flattening and deposition molten powder splats. Corresponding to the average porosity, the micro-hardness of the coatings is also presented in Fig.3, which increased also with the thickness.

In conclusion, the thickness of zirconia coatings slightly lowered the coating porosity but the mechanical performance of hardness was clearly improved for thicker coatings. Both the large thickness and high hardness of sprayed zirconia coatings were good for the thermal barrier coating application of the coatings. In particulars, high hardness should be good for raising the scratch durability of the coatings.

\subsection{Scratch test of DLC film on aluminum substrate} and the effect of the hard interface layer

Figure 4(a) shows the results of the scratch test of the diamond-like carbon (DLC) film on aluminum alloy substrate. Figure 4(b) is also the result for the case of the $\mathrm{DLC}$ film with $\mathrm{SiC}_{\mathrm{x}}$ interlayer on aluminum alloy
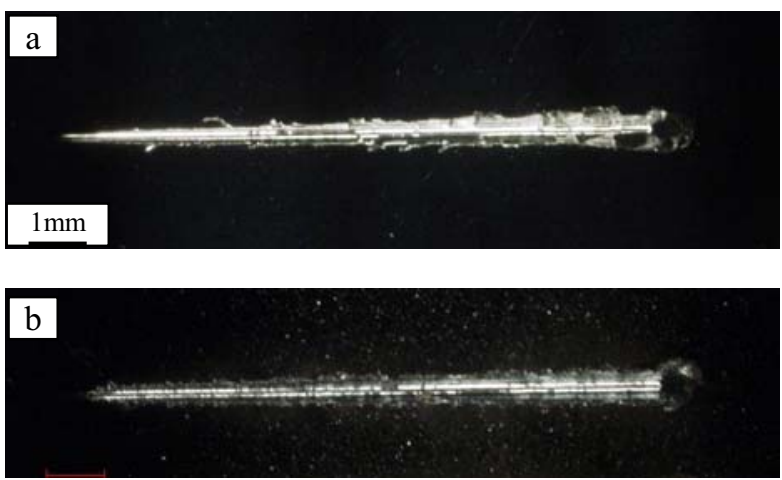

Fig.4 The optical photos of the scratch tracks of DLC Films without and with $\mathrm{SiC}$ interlayer on the aluminum alloy substrate. (a) without $\mathrm{SiC}$ interlayer, (b) with $\mathrm{SiC}$ interlayer. substrate. The comparison between (a) and (b) shows that the adhesion failure of DLC films was improved by the interlayer of a hard ceramic SiC film on the soft metal substrate. Thus the adhesion between DLC film and the substrate become stronger by the hard ceramic interlayer. This adhesion failure of DLC films is caused by the separation of the DLC films from the substrates.
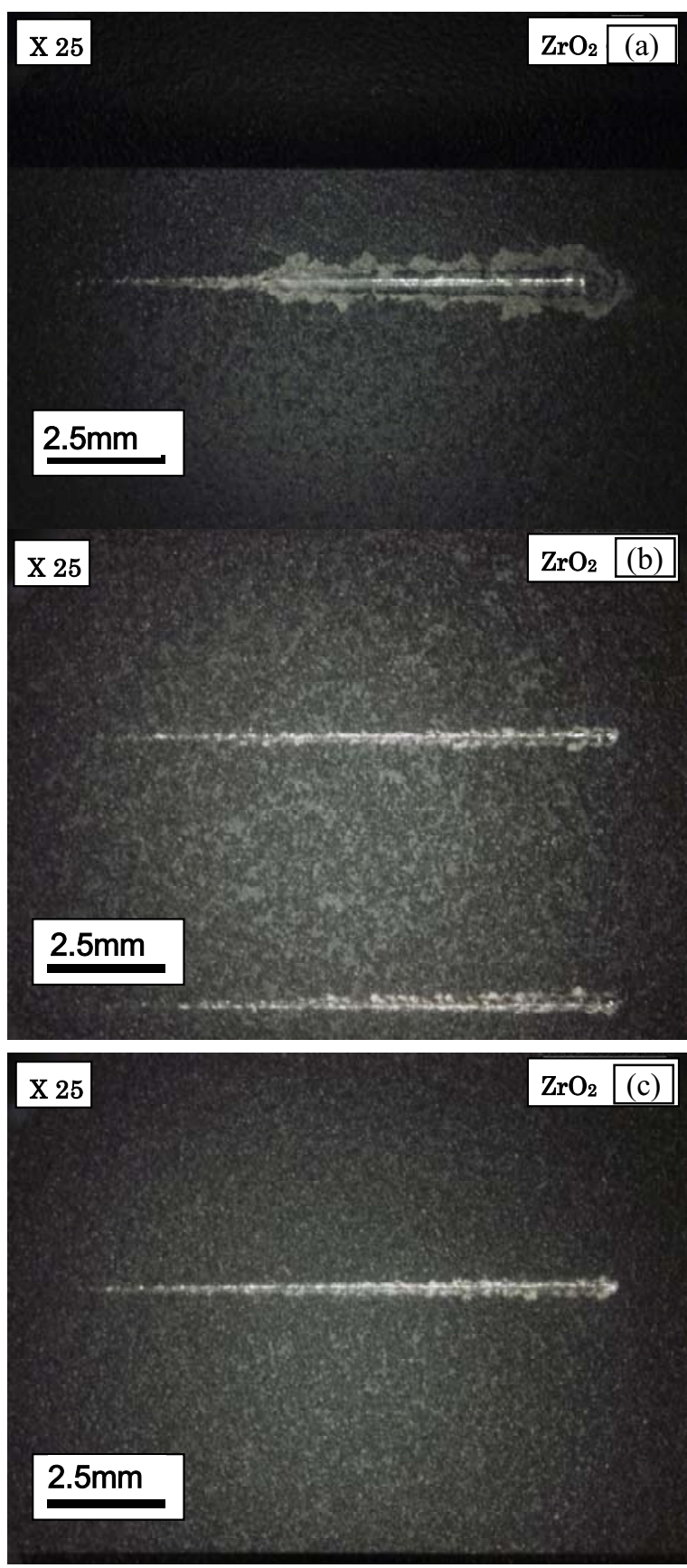

Fig.5 The optical photos of the scratch tracks of DLCcovered zirconia coating with different thickness, where the thickness of zirconia coating is (a) $65 \mu \mathrm{m}$, (b) $180 \mu \mathrm{m}$ and (c) $210 \mu \mathrm{m}$. 


\subsection{Scratch durability of DLC film on zirconia coatings}

The DLC films were deposited on the zirconia coatings after polishing the coating surfaces. The surface friction was greatly improved by the DLC deposition compared with the as-sprayed coatings. The coating roughness was also improved by the pre-polishing.

Figure 5 shows the optical photos of the scratch traces of DLC covered zirconia coatings with different thickness, where the thickness of zirconia coating is (a) $65 \mu \mathrm{m}$, (b) $180 \mu \mathrm{m}$ and (c) $210 \mu \mathrm{m}$. From the photos in Fig 5, the scratch traces for different thickness appear very different. For the thinner coating $(65 \mu \mathrm{m})$, the trace shows the clear flakings after very short scratches (about $3 \mathrm{~mm}$ in length), while for thicker coatings $(180 \mu \mathrm{m}$ and $210 \mu \mathrm{m})$ the traces show almost little large flaking until the end of scratching, but a little bit of chipping of DLC film. The results mean that thicker coatings could sustain much higher scratch stresses than thinner coatings because thicker coatings showed higher hardness.

Figure 6 shows the acoustic emission-load graphs for the scratch measurements of Fig. 5. Figure 7 gives the critical loads obtained from the graphs in Fig 6, which indicated the DLC film adhesion. The figures show that thinnest zirconia coating is the weakest in adhesion of DLC film and the two thicker coatings give almost the same adhesion, which is in coincident with the tendency of scratch track appearances shown in Fig 5. Although the stress threshold of DLC film crack is clearly affected by the zirconia coating thickness, the adhesion of DLC films only varies a little (about 20\%) by the zirconia coating thickness, which is because the DLC film adhesion is affected by the distortion of substrate.

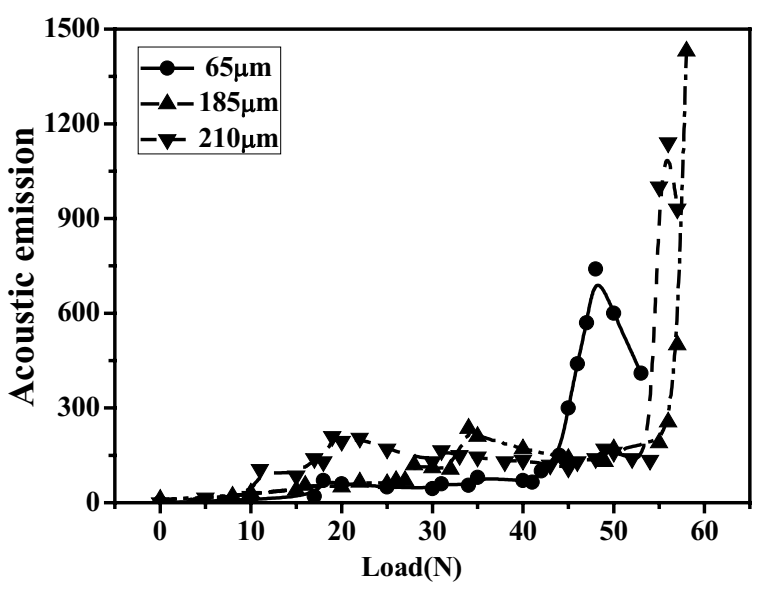

Fig.6 Acoustic emission-load graphs for the scratch measurements of Fig. 5. (The scratch graphs of the DLC-covered $\mathrm{ZrO}_{2}$ coatings.)

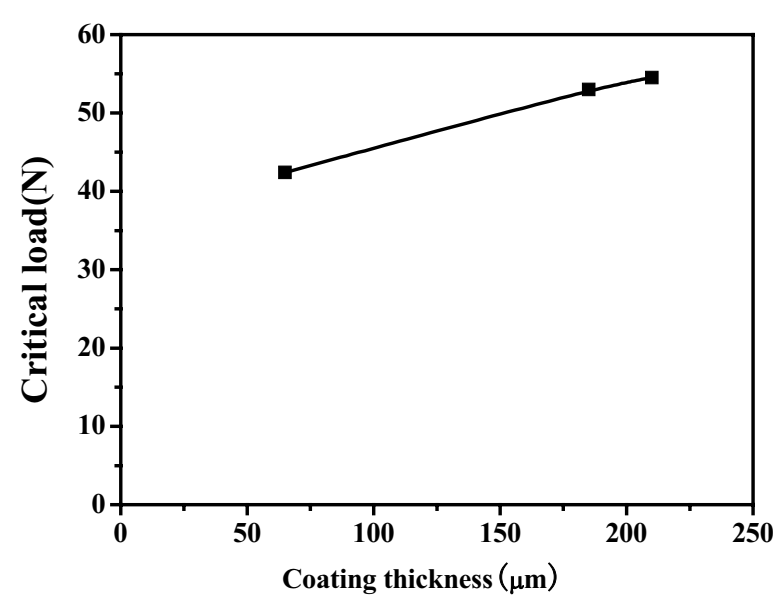

Fig.7 The scratch critical load v.s the thickness of DLCcovered $\mathrm{ZrO}_{2}$ coatings.

\subsection{Mechanism for the adhesion failure of DLC film on zirconia coatings}

The adhesion failure of films and/or coatings is caused by two different mechanisms: one is the separation of the coatings from the substrates and the other is the breaking of the coating-themselves under mechanical load.

During scratch tests, the two different mechanisms are both possible to happen. Therefore, the mechanism of adhesion failure of films can be generally revealed by scratch test. From the microscopic optical photos of the scratch tracks, the adhesion failure of DLC film on thinner zirconia sprayed coatings is due to the breaking of the DLC films by the distortion of aluminum substrate, while the adhesion failure of DLC films on thicker zirconia coatings is due to the chipping of DLC film itself.

\section{Conclusions}

In this paper, zirconia coatings with different thickness were prepared on aluminum alloy substrates using gas tunnel type plasma spraying. For comparison investigation, some of the sprayed coating samples were chosen to deposit DLC films for improvement of surface lubrication. The micro-hardness and adhesion strength or scratch durability of the DLC-covered zirconia coatings on aluminum alloy substrate were investigated and the following conclusions were reached:

(1) The scratch tests showed that the DLC films on the thicker sprayed zirconia coatings were stronger in scratch durability.

(2) The hardness and porosity of zirconia coatings showed that thicker coatings had higher hardness and lower porosity. Thus thicker coatings with higher hardness presented stronger scratch durability.

(3) The adhesion failure of DLC film on thinner zirconia coatings is due to the flaking of the DLC films by the distortion of the substrate, while the adhesion failure 


\section{Bonding Strength of DLC Film on Zirconia Coating Prepared by Gas Tunnel Type Plasma Spraying}

of DLC film on thicker coatings is due to the chipping of DLC film itself.

\section{Acknowledgement}

This work was financially supported by Grant-in-Aid with No.16.04371 and No.15360449 from Japan Society for Promotion of Science. The authors would like to thank Mr.Yano and Dr. Shanmugavelayutham for their helps in experiments and the image analysis.

\section{References:}

1) X.Q.Cao, R.Vassen and D.Stoever, Ceramic materials for thermal barrier coatings, J. Euro. Ceramic Society, 24(2004), pp.1-10.

2) R. Vassen, X. Cao, F. Tietz, D. Basu and D. Stover, Zirconates as new material for thermal barrier coatings. J. Am. Ceram. Soc., 83(8)(2000), pp.2023.

3) J. Kaspar and O. Ambroz, Plasma coatings as thermal barriers based on zirconium oxide with yittrium oxide. In the first Plasma-technique-symposium, Vol.2, (Lucerne Switzerland, 18-20, May 1988), Ed. H.Eschnauer, P.Huber, A.R.Nicoll and S.Sandmeier. Plasma-Technique AG, Wohlen, Switzerland, (1988) pp.155-166.

4) R.Vassen and D.Stover, Functional gradient materials and surface layers prepared by fine particle technology, Kluwer Academiac Publishers, Netherlands, (2001), pp.199.

5) V.Teixeira, M.Andritschky, W.Fischer, H.P. Buchkremer and D.Stover, Analysis of residual stresses in thermal barrier coatings, J. Mater. Process. Technol. 92-93 (1999), pp.209-216.

6) G.Qian, T.Nakamura and C.C.Berndt, Effects of thermal gradient and residual stresses on thermal barrier coating frature, Mech. Mater. 27(1998), pp.91-110

7) Y.Arata, A.Kobayashi, Y.Habara and S.Jing, Gas tunnel type plasma spraying, Trans. of JWRI, 15-2(1986), pp.227.

8) Y.Arata, A.Kobayashi,and Y.Habara, Ceramic coatings produced by means of a gas tunnel type plasma jet: J. Applied Physics, 62(1987), pp.4884.

9) A.Kobayashi, Formation of high hardness zirconia coatings by gas tunnel type plasma spraying, Surf .Coat. Technol., 90(1990), pp.197-202.

10) V.Teixeira, M. Andritschky, W.Fischer, H.P. Buchkremer and D. Stover, Effects of deposition temperature and thermal cycling on residual stress state in zirconia-based thermal barrier coatings, Surf. Coat. Technol. 120-121(1999), pp103-111. 